\title{
Insulinotropic Activity in the Serum of Obese and Nonobese Infants and Children
}

\author{
PENTTI LAUTALA, HANS K. ÅKERBLOM, KAUKO KOUVALAINEN, AND JULIO M. MARTIN \\ Department of Pediatrics, University of Oulu, The Nordic Council for Arctic Medical Research, Oulu, Finland \\ and The Research Institute, The Hospital for Sick Children, Toronto, Ontario, Canada
}

\begin{abstract}
The ability of a serum fraction, mol wt 1000 5000 , to stimulate insulin release in vitro was studied in 123 obese and normal weight children aged 0-17 yr. The sera were fractionated by serial molecular filtration after treatment with urea. Stimulation of insulin release was determined with a bioassay using isolated rat islets in perifusion. The islet-stimulating activity was found in all obese children less than the age of $10 \mathrm{yr}$ and in the majority of the obese children older than $10 \mathrm{yr}$ of age. In normal weight children the activity was also found in the majority of infants, but was infrequent in older children. The serum islet-stimulating activity was positively correlated with the duration and degree of obesity and with linear growth rate. The molecular structure and origin of the insulinogenic activity in the serum is still unknown. In high-performance liquid chromatography it has the same elution characteristics as the hypothalamic insulin-glucagon liberin. The present results suggest a role for the serum islet-stimulating activity in the pathogenesis of obesity. (Pediatr Res 20: 720-723, 1986)
\end{abstract}

\section{Abbreviations}

OGTT, oral glucose tolerance test

IRI, immunoreactive insulin

IRG, immunoreactive glucagon

VIP, vasoactive intestinal polypeptide

Obesity is the most common nutritional disorder in developed countries. A frequency of $35 \%$ was reported in North America (1). Obesity starting in childhood tends to continue into adulthood and thereby increases the risk for diseases of the cardiovascular and musculoskeletal systems. An association with maturityonset diabetes mellitus is also well documented $(2,3)$.

Obesity is nearly always associated with an altered glucose homeostasis manifested as hyperinsulinemia and insulin resistance $(4,5)$. An elevated concentration of circulating insulin seems to be the primary phenomenon in obesity preceding the changes in glucose and lipid metabolism (6). The initial hyperinsulinemia in obesity is independent of hyperphagia (7) but its mechanism is still largely unknown. Neural and neurohumoral mechanisms have both been suggested $(8,9)$.

We have earlier reported the existence of islet-stimulating activity in the serum of obese children (10). In this cross-sectional study we report the age-dependent association of islet-stimulating activity in the serum fractions, mol wt 1000-5000, of children

Received April 29, 1985; accepted March 13, 1986.

Correspondence Dr. Pentti Lautala, Department of Pediatrics, University of Oulu, SF-90220 Oulu, Finland.

Supported by the Sigrid Jusélius Foundation and Nordisk Insulin Fond (H.K.A.) the Medical Research Council of Finland (P.L., H.K.A.). with obesity. Also the relationship between the serum isletstimulating activity and glucose tolerance as measured by oral glucose tolerance test in obese and nonobese children was evaluated.

\section{SUBJECTS AND METHODS}

Subjects. We studied 64 obese ( 32 boys, 32 girls) and 59 nonobese ( 37 boys, 22 girls) children aged $0-17$ yr. Obesity was defined on the basis of standard height and weight charts for Finnish children, on a criterion of an excess in weight of 2 SD or more above the mean for the age at which the corresponding height was projected to the 50th percentile. Our obese group had a weight excess of $25 \%$ or more above the mean (range $2.0-8.8$ SD). The median duration of obesity in children less than $10 \mathrm{yr}$ of age was $3.2 \mathrm{yr}$ and in those aged $10 \mathrm{yr}$ or older $6.7 \mathrm{yr}$. Linear growth rate $(\mathrm{cm} / \mathrm{yr})$ during the preceding year and any deviation of height from the mean for the age were also recorded. Duration of obesity was determined from the growth charts using the above mentioned criteria. The islet-stimulating activity was determined in the sera of all 123 children and an OGTT was performed on 32 obese and 10 normal weight children. Table 1 shows the age distribution of the children studied.

Bioassay of the serum islet-stimulating activity. Blood specimens of approximately $15 \mathrm{ml}$ for the determination of the serum islet stimulating activity were taken in connection with OGTT or blood sampling for some other clinical purpose. In newborn infants the samples were taken from the first outdrawing at the beginning of a blood exchange transfusion occasioned by hyperbilirubinemia. Sera were separated after clot retraction and stored at $-20^{\circ} \mathrm{C}$ until fractionated. Immunoreactive insulin was always determined in the samples before the fractionation.

The sera were first treated with urea, $0.643 \mathrm{~g} / \mathrm{ml}$ of serum, to arrest enzyme activity and to split the active subsance(s) from albumin bonds, because in an earlier study (11) it was shown that the islet-stimulating activity is associated with plasma albumin fraction. The samples were then filtrated through Amicon (Amicon B.V., Oosterhout, Holland) membranes XM-50, UM10 , DM-5, and UM-2, with molecular weight limits of 50,000 , $10,000,5,000$ and 1,000 , respectively. The material retained by the UM-2 membrane (mol wt 1000-5000 daltons) was washed with $0.9 \% \mathrm{NaCl}$ until the concentration of urea was less than 5 $\mathrm{mmol} /$ liter. This serum fraction, referred to below by the symbol "Fr," usually at a volume of 3-6 $\mathrm{ml}$ was stored at $-20^{\circ} \mathrm{C}$ until used. Immunoreactive insulin was determined in the Frs (12) and in some cases IRG was also determined (13).

The islet-stimulating activity in the Frs was assessed by a biological method using a modification of the perifusion technique of Lacy et al. (14). For each experiment isolated islets (15) were obtained from two Wistar rats weighing 250-350 g. Approximately 50 islets were placed in the tissue chamber (Millipore capsule). A peristaltic pump located distally to the chamber ensured a constant perifusion flow of $1 \mathrm{ml} / \mathrm{min}$. A three-way 
Table 1. Age distribution of the children studied

\begin{tabular}{lccccc}
\hline & & \multicolumn{4}{c}{ Age group } \\
\cline { 3 - 6 } & Newborns & $1 \mathrm{mo}-1.0 \mathrm{yr}$ & $1.1-9.9 \mathrm{yr}$ & $\geq 10 \mathrm{yr}$ & Total \\
\hline Obese & & 1 & 24 & 39 & 64 \\
Normal wt & 7 & 11 & 28 & 13 & 59 \\
Total & 7 & 12 & 52 & 52 & 123 \\
\hline
\end{tabular}

stopcock, placed immediately above the chamber, allowed the admission of either perifusion buffer or the test sample with a minimum dead space. The basic perifusion medium was KrebsRinger bicarbonate buffer with $0.2 \%$ bovine serum albumin, 2 $\mathrm{mM} \mathrm{CaCl}_{2}$, and $5.5 \mathrm{mM}$ glucose. It was maintained at $\mathrm{pH} 7.4$ by continuous gassing with $5 \% \mathrm{CO}_{2}-95 \% \mathrm{O}_{2}$.

Figure 1 shows the perifusion device. In each experiment basal insulin release was determined during $10 \mathrm{~min}$ following a $45-$ min equilibration period. Then $0.5 \mathrm{ml}$ of a $\mathrm{Fr}$ was admitted through the stopcock (S). Perifusion with basal medium was continued for approximately $25 \mathrm{~min}$ thereafter. By this time insulin release had returned to basal levels. As a control $0.5 \mathrm{ml}$ of normal saline $(\mathrm{NaCl})$ was introduced and 11 min later islets were stimulated with $0.5 \mathrm{ml}$ of $20 \mathrm{mM}$ glucose (Fig. 2). The insulin release was calculated and expressed in $\mu \mathrm{U} / \mathrm{min}$. Each batch of fresh islets was never used for testing more than three samples within a period of less than $6 \mathrm{~h}$.

Increases of insulin release exceeding by $2 \mathrm{SD}$ the mean basal release at the particular experiment were considered as significant stimulations and the respective Frs regarded as positive (qualitative results). This type of analysis was dictated by the wellknown batch-to-batch variability of the secretory activity of the islets that makes it a necessity to compare the relative rather than the absolute changes.

As an additional control perifusion experiments using "shamserum" containing bovine serum albumin, $5 \mathrm{mM}$ glucose, and amino acids in normal saline and treated identically with the serum samples were performed. In three experiments no stimulation of insulin release was observed.

The reproducibility of the bioassay was tested and confirmed by repeating the assay twice in 17 cases, three times in two cases, and five times in one case. The positive sera gave positive results in every experiment with the interexperimental coefficient of variation of $21.3 \%$.

Islet-stimulating activity was quantitated by calculating the area of insulin release above the baseline during the first $5 \mathrm{~min}$ in response to the $\mathrm{Fr}$ in percent of the response elicited by 20 $\mathrm{mM}$ glucose stimulation. All results were expressed per $\mathrm{ml}$ of the original serum sample (Fig. 2). For the OGTT, $1.7 \mathrm{~g}$ of glucose per $\mathrm{kg}$ of body weight was given after an overnight fasting. Blood glucose and serum IRI (12) were determined in the fasting samples and at 30,60, 90, 120, and $180 \mathrm{~min}$ after glucose ingestion. Serum IRI was determined from every sample tested for islet-stimulating activity.

Statistical methods. Comparison of two proportions (unpaired cases) was carried out according to Armitage (16), and Student's $t$ test was used to compare the differences between the mean IRI and blood glucose values of the various groups of subjects. Logarithmic values were used in the analysis of the serum IRI as the individual values skewed to the right but became normal after logarithmic transformation. Correlations between various physical and clinical parameters and the quantitative islet-stimulating activity of the Frs were studied by regression analysis.

\section{RESULTS}

Most Frs contained no detectable IRI, in some cases (24/123) concentrations between 2 and $5 \mu \mathrm{U} / \mathrm{ml}$ were found. IRG was determined in 21 Frs. Concentrations of IRG were similar in the Frs of normal weight and obese children (means 0.71 and 0.78 $\mathrm{ng} / \mathrm{ml}$, respectively). There was no correlation between the IRG

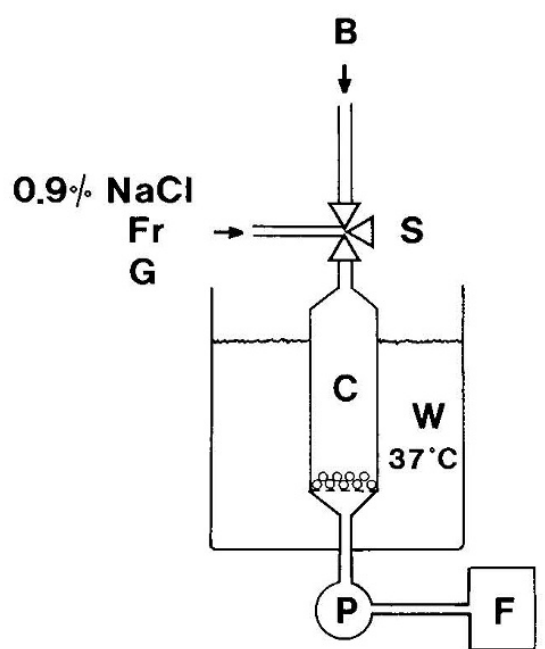

Fig. 1. The perifusion device. Symbols represent baseline perifusion medium $(B)$, stopcock $(S)$, test substances $(\mathrm{G}, \mathrm{Fr}, 0.9 \% \mathrm{NaCl})$, islet chamber $(C), 37^{\circ} \mathrm{C}$ waterbath, perifusion pump $(P)$, and fraction collector $(F)$.

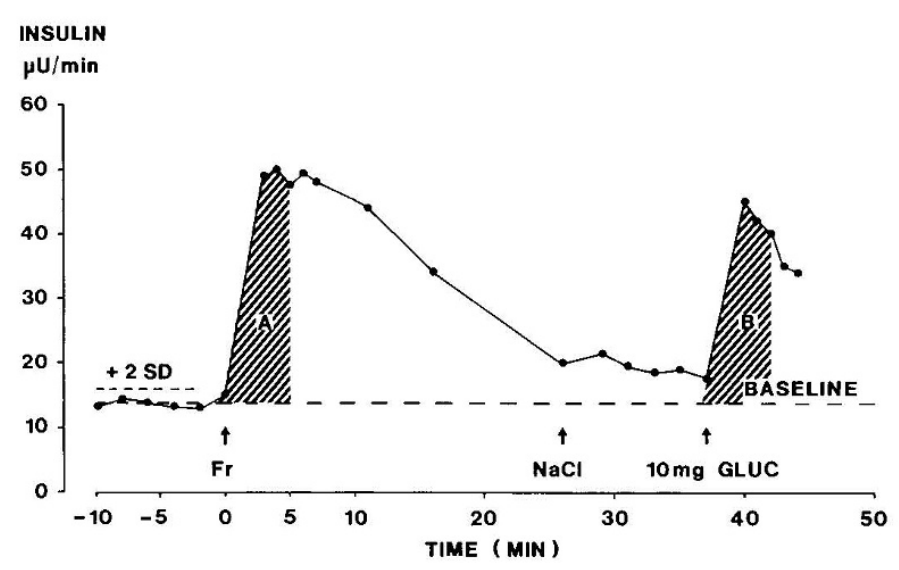

Fig. 2. An example of positive result in the bioassay. After baseline perifusion islets are stimulated with the serum fraction, $\mathrm{Fr}$, at 0 minutes. At $25 \mathrm{~min} 0.9 \% \mathrm{NaCl}$ and $11 \mathrm{~min}$ thereafter $10 \mathrm{mg}$ of glucose were introduced, all in a volume of $0.5 \mathrm{ml}$. Quantitation of the insulinotropic activity was calculated by the equation $\mathrm{A} \times \mathrm{V}_{\mathrm{Fr}} \times 100: \mathrm{B} \times \mathrm{V}_{\mathrm{s}} \times 0.5$, where $V_{F r}=$ total volume of serum fraction, $V_{s}=$ volume of original serum sample, $A=$ area of insulin release above baseline in response to Fr and $B=$ area of insulin release above baseline in response to glucose.

and the islet-stimulating activity in the Frs. The Frs did not contain detectable amounts of glucose or amino acids. Figure 2 gives an example of a typical positive result in the bioassay.

Table 2 gives the proportion of sera positive (qualitative result) for islet-stimulating activity in obese and normal weight children in four age groups. In obese children we found a higher proportion of positive sera in the age groups $1.1-9.9 \mathrm{yr}(100 \%)$ and more than $10 \mathrm{yr}(74.4 \%)$ than in normal weight children $(55.5$ and $26.8 \%$, respectively, $p<0.01$ ). The proportion of positive sera decreased with age from 1 month on in normal weight children. A similar decrease was observed in obese children only after $10 \mathrm{yr}$ of age. In newborn infants the islet-stimulating activity was found in only two of the seven sera studied.

The quantitation of the islet-stimulating activity gave a wide range of values from 0 to $381 \% / \mathrm{ml}$ which is not uncommon for a bioassay. As a result of this the mean values for obese, 47.8 , and for nonobese, 33.7, were not significantly different. Nevertheless, the islet-stimulating activity tended to be low in nonobese children and in children more than $10 \mathrm{yr}$ of age (Table 3 and Fig. 3). In obese children 1.1-9.9 yr of age the serum islet- 
Table 2. Proportions of sera positive for islet-stimulating activity in obese and normal wt children in four age groups

\begin{tabular}{lcccc}
\hline & & \multicolumn{3}{c}{ Age groups } \\
\cline { 3 - 5 } & Newborns & $1 \mathrm{mo}-1.0 \mathrm{yr}$ & $1.1-9.9 \mathrm{yr}$ & $\geq 10 \mathrm{yr}$ \\
\hline Obese & & $1 / 1$ & $24 / 24^{*}$ & $23 / 39 \dagger$ \\
Normal wt & $2 / 7$ & $8 / 11$ & $14 / 28^{*}$ & $4 / 13 \dagger$ \\
Total & $2 / 7$ & $9 / 12$ & $40 / 52$ & $33 / 52$ \\
\hline
\end{tabular}

$* \dagger p<0.01$.

Table 3. Distribution of quantitative islet-stimulating activity at various ages in normal wt and obese infants and children

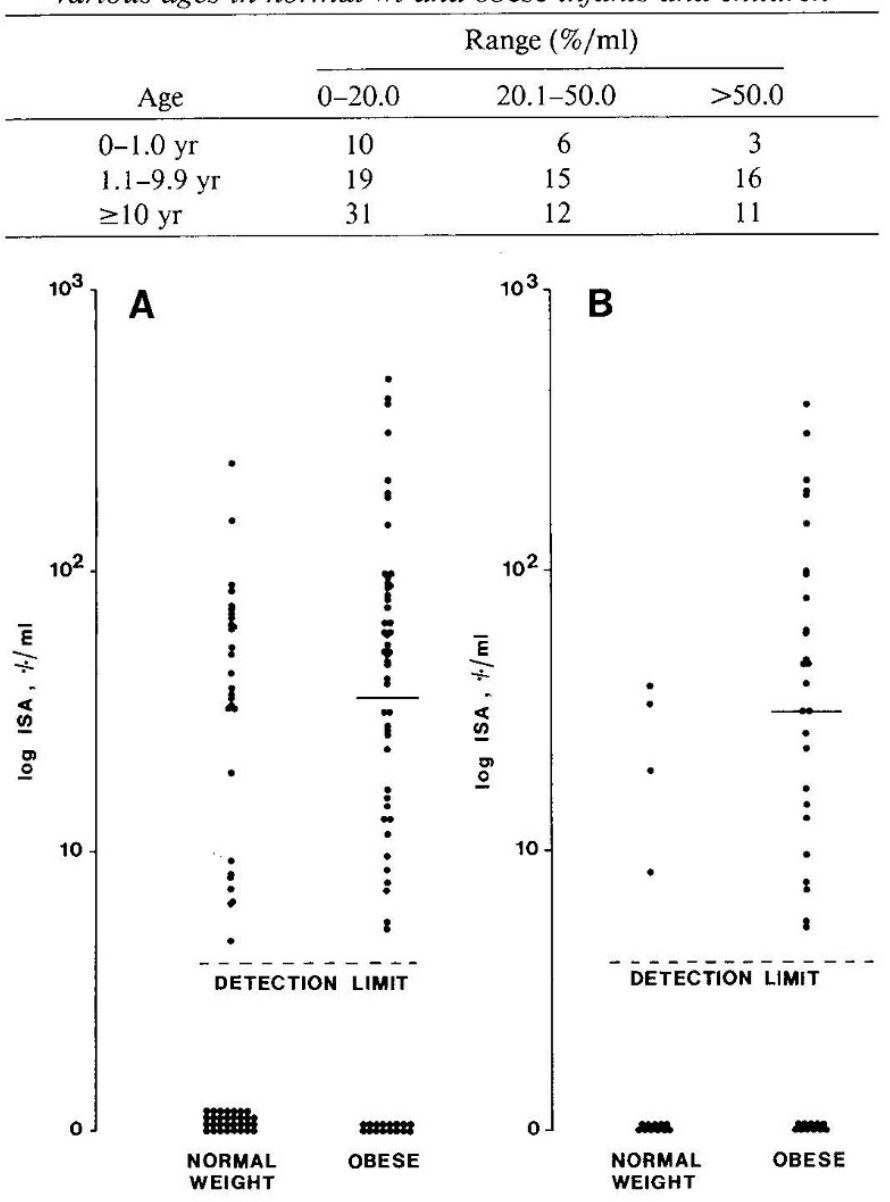

Fig. 3. Distribution of serum islet-stimulating activity (log ISA, \%/ $\mathrm{ml})$ in obese and normal weight children less than $(A)$ and more than (B) $10 \mathrm{yr}$ of age.

stimulating activity was positively correlated to the duration of obesity $(r=0.41, p<0.05$, Fig. $4 A$ ) and the degree of obesity $(r$ $=0.46, p<0.02$, Fig. $4 B)$. In this age group a weak positive correlation between linear growth rate and the insulinotropic activity in the Frs was found $(r=0.203, p<0.05)$. This correlation disappeared after the age of $10 \mathrm{yr}$.

Glucose tolerance was normal in all the children studied. Obese children had higher serum IRI at fasting and during the test compared with normal weight children. We could not demonstrate a correlation between the serum islet-stimulating activity and serum IRI.

\section{DISCUSSION}

Our study shows that human serum contains material of mol wt 1000-5000 capable of stimulating insulin release in rat islets in vitro. The occurrence of serum islet-stimulating activity is higher in obese than in normal weight children. Its occurrence in normals seems to be inversely related with age, being higher in infants ( 1 month to $1 \mathrm{yr}$ old) and steadily decreasing thereafter.
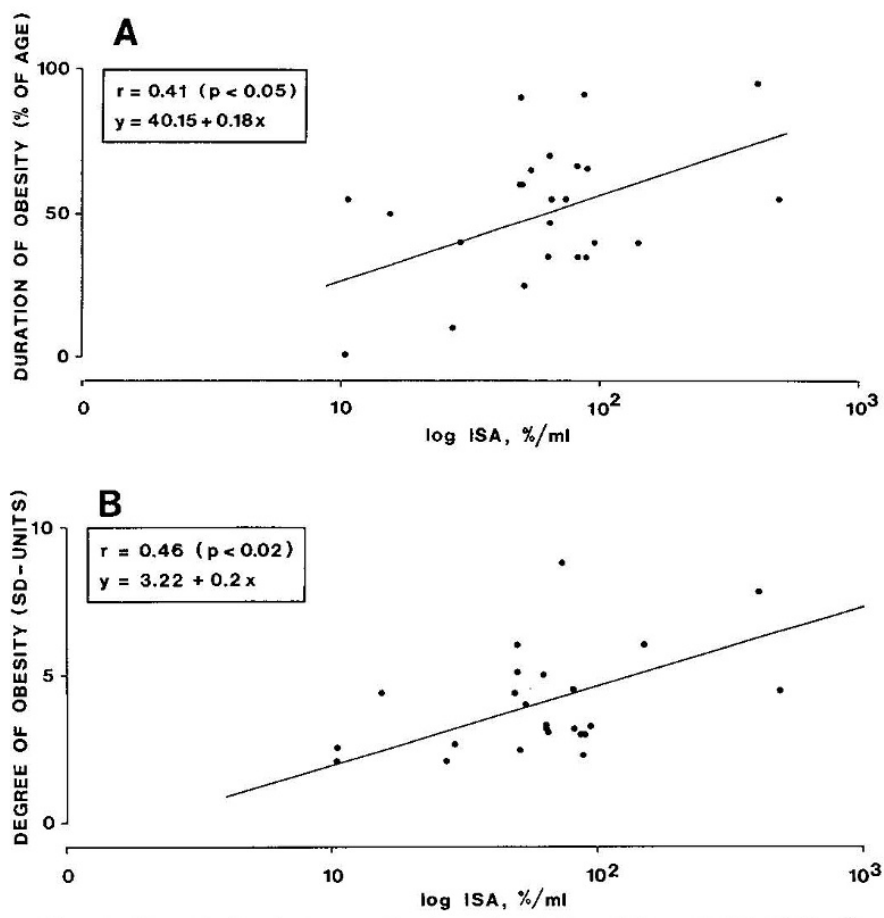

Fig. 4. Correlation between the duration $(A)$ and degree $(B)$ of obesity and the serum islet-stimulating activity $(\log \mathrm{ISA}, \% / \mathrm{ml})$.

The finding of a small proportion of positive sera among newborn infants could be due to the different sampling conditions used for that age group. The present findings thus suggest that the serum islet-stimulating activity could be associated with the regulation of body weight and linear growth. In obese individuals the activity is correlated with the severity and duration of the obese state. No correlation between the islet-stimulating activity and serum IRI at fasting or during OGTT was demonstrated.

The chemical nature and origin of the active material in the Frs are not known. The fractionation process limits the possible active substances to those of mol wt between 1000 and 5000 . Several polypeptide hormones of this molecular weight range from intestinal mucosa, pancreas, and hypothalamus have been described recently (17-20), many of which can modify glucose metabolism by either affecting the endocrine pancreatic function or through a direct action on peripheral tissues.

Hypothalamic tissue containes material capable of stimulating insulin release in vitro in rat islets (21). This hypothalamic material has been recently characterized as a tridecapeptide of apparent mol wt 1350 and named insulin-glucagon liberin for its ability to enhance both insulin and glucagon secretion (22). The active material in our Frs, when submitted to high-pressure liquid chromatography, has the chromatographic characteristics of bovine hypothalamic insulin glucagon-liberin (23). Of the possible active peptides gastric inhibitory peptide, bombesin, pancreatic glucagon, and $\beta$-endorphin have elution characteristics clearly different from the insulinotropic activity of our Frs.

Glucagon-like immunoreactivity in the serum is a heterogenous group of peptides, some of which fall in the molecular weight range of our Frs (24). In our serum fractions the level of IRG was definitively lower than the minimum required for the stimulation of insulin release reported by other investigators (25). VIP is a polypeptide of appropriate molecular weight for appearance in the Frs. VIP stimulates insulin release in vitro, but this effect, most likely, is mediated through the vagus nerve $(26,27)$. The concentrations of active material in our bioassay would probably be far too low for the VIP to produce stimulation of insulin release. Also, VIP has a lipolytic effect on isolated fat cells, whereas we found our Frs in many instances to be lipogenic.

Gastrins are known to influence insulin release but this effect depends on glucose concentrations higher than used in our 
bioassay. In our Frs the concentrations of gastrins would not be high enough to have effect in insulin release in vitro (28). Small C-terminal peptides of cholecystokinin have been shown to increase insulin release. These peptides could have physiological significance in the neural regulations of endocrine pancreas (29). The most active of these peptides would, however, be below the molecular weight range of our Frs, and for the larger ones the concentrations needed for biological activity would be too high.

There is also a report on an insulin secretagogue isolated from the intermediate lobe of rat pituitary having similarities with the C-terminal end of ACTH (30).

The correlation between the serum islet-stimulating activity and linear growth rate could simply be an expression of its presence in the very young children in whom the the growth rate is the highest. On the other hand, it could suggest a role for the islet-stimulating activity in the regulation of linear growth as insulin is a major growth promoting hormone during fetal life and possibly also in infancy and childhood. The correlation between the islet-stimulating activity and various other parameters could also be affected by the semiquantitative nature of the bioassay used.

Hypothalamic regulation of growth has been suggested recently. Growth-hormone deficient children may in some cases grow even faster than normal after operative treatment of craniopharyngeoma. This increased growth rate is associated with hyperinsulinemia and obesity (31). Wheather this phenomenon could be attributed to serum islet-stimulating activity remains to be investigated.

Even when the active substance(s) is not yet known our study shows that there is in the human serum a factor capable of stimulating insulin release in vitro and this activity is clearly associated with obesity. Our results also show that the serum islet-stimulating activity could have a role in the development of obesity in children. In addition, the study suggests that the insulinogenic activity in the serum could be associated with the regulation of linear growth.

Acknowledgments. Excellent technical assistance was given by Ms. Eeva Luomala, Mr. Heinz-Josef Christophiliemk, and Ms. Sirpa Anttila.

\section{REFERENCES}

1. Weil WB 1977 Current controversies in childhood obesity. J Pediatr 91:175187

2. Charnley E, Goodman HC, McBride M, Lyon B, Pratt R 1976 Childhood antecedents of adult obesity. N Engl J Med 295:6-9

3. Woodhouse SP 1976 Obesity as a risk factor. Med J Aust (special suppl 1):1112

4. Rabinowitz D, Zierler KL 1962 Forearm metabolism in obesity and its response to intra-arterial insulin. Characterization of insulin resistance and evidence for adaptive hyperinsulinism. $\mathrm{J}$ Clin Invest 41:2173-2181

5. Breidahl HD 1976 Carbohydrate tolerance and obesity. Med J Aust (special suppl 1):9-10
6. Jeanrenoud B 1979 Insulin and obesity. Diabetologia 17:133-138

7. Martin JM, Konijdendijk W, Bouman PR 1974 Insulin and growth hormone secretion in rats with ventromedial hypothalamic lesion maintained on restricted food intake. Diabetes 23:203-208

8. Hill DE, Mayes S, DiBattista D, Lockhart-Ewart R, Martin JM 1977 Hypothalamic regulation of insulin release in rhesus monkeys. Diabetes 26:726-731

9. Berthoud H-R, Jeanrenoud B 1979 Acute hyperinsulinism and its reversal in anesthetized rats. Endocrinology 105:146-151

10. Lautala P, Akerblom HK, Kouvalainen K, Martin JM 1977 A hypothalamic islet-stimulating factor and childhood obesity. In: Chiumello G, Laron Z (eds) Recent Progress in Pediatric Endocrinology. Serono Symposia, Vol 12. Academic Press, London, pp 235-239

11. Martin JM, Mok CC, Penfold J, Howard NJ, Crowne D 1973 Hypothalamic stimulation of insulin release. J Endocrinol 58:681-682

12. Herbert V, Lau K-S, Gottlieb CW, Bleicher SJ 1965 Coated charcoal immunoassay of insulin. J Clin Endocrinol 25:1375-1384

13. Heding LG 1971 Radioimmunological determination of pancreatic and gut glucagon in plasma. Diabetologia 7:10-19

14. Lacy PE, Finke EH, Conant SM, Naber S 1976 Long-term perifusion of isolated rat islets in vitro. Diabetes 25:484-491

15. Lacy PE, Kostianovsky M 1967 Method for the isolation of intact islets of Langerhans from the rat pancreas. Diabetes 16:35-39

16. Armitage P 1971 Statistical Methods in Medical Research. Blackwall Scientific Publications, London

17. Grossman MI, Adelson JW, Rothman SS, Brown JC, Said SI, Lin T-M, Chance RE, Gerring EL, Gregory H, Glass GBJ, Anderson S, Masset ES, Sasaki H, Faloona GR, Unger RH, Creutzfeldt W, Kokas E, Thompson JC 1974 Candidate hormones of the gut. Gastroenterology 67:730-755

18. Brown B, Vale W 1976 Effects of neurotensin and substance P on plasma insulin, glucagon and glucose levels. Endocrinology 98:819-822

19. Ishida $\mathrm{T} 1977$ Stimulatory effects of neurotensin on insulin and gastrin secretion in dogs. Endocrinol Jpn 24:335-342

20. Creutzfeld W 1980 Insulinotropic factors of the gut-the broadening incretin concept. Gastroenterology 78:1631-1632

21. Idahl L-A, Martin JM 1971 Stimulation of insulin secretion by a ventrolateral hypothalamic factor. J Endocrinol 51:601-602

22. Brouwer GH, Lamptey MS, Martin JM 1982 Isolation and partial characterization of insulin-glucagon liberin from bovine hypothalamus. Life Sci 30:703-710

23. Knip M, Lautala P, Åkerblom HK, Kouvalainen K, Martin JM 1983 Partial purification of an insulin-releasing activity in human serum. Life Sci 33:2311-2319

24. Tanaka R, Matsuyama T, Shina K, Sawazaki N, Tarui S, Kumahara Y 1977 Insulin releasing activity of gastrointestinal glucagon-like immunoreactive material in perfused rat pancreas. Endocrinol Jpn 24:575-579

25. Schaubert B, Brown JC, Frerichs H, Creutzfeld W 1977 Gastric inhibitory polypeptide: effect on glucose induced insulin release from isolated rat pancreatic islets in vitro. Diabetologia 11:483-484

26. Creutzfeldt W 1979 The incretin concept today. Diabetologia 16:75-85

27. Bishop AE, Polak JM, Green C II, Bryant MG, Bloom SR 1980 Location of VIP in the pancreas of man and rat. Diabetologia 18:73-78

28. Lindkaer Jensen S, Rehfeldt JF, Holst JJ, Fahrenburg J, Nielsen OV, Schaffalitsky de Muckadell OB 1980 Secretory effects of gastrins on isolated perfused porcine pancreas. Am J Physiol 238:E186-E192

29. Rehfeldt JF, Larsson L-I, Golterman NR, Schwartz TW, Holst JJ, Jensen SL, Morley JS 1980 Neural regulation of pancreatic hormone secretion by the C-terminal tetrapeptide of CCK. Nature 284:33-38

30. Beloff-Chain A, Dunmore S, Morton J 1980 B-cell tropin, a peptide of the pituitary pars intermedia which stimulates insulin release. FEBS Lett 117:303-307

31. Bucher H, Zapf J, Torresani T, Prader A, Froesch ER, Illig R 1983 Insulinlike growth factors I and II, prolactin, and insulin in 19 growth hormonedeficient children with excessive, normal, or decreased longitudinal growth after operation for craniopharyngeoma. N Engl J Med 309:1 142-1146 